\title{
Efecto analgésico del parche de capsaicina al $8 \%$ a través del receptor vaniloide TRPV-1, en un paciente con enfermedad de Parkinson y dolor neuropático localizado
}

\author{
Analgesic effect of the capsaicin $8 \%$ patch through the \\ TRPV-1 receptor in a case of parkinson desease with \\ located neuropathic pain
}

\author{
A. Alonso Cardaño ${ }^{1}$ D. García Rivera² y A. García Rodríguez²
}

1 Unidad de Dolor, Servicio de Anestesiología y Reanimación, Complejo Asistencial Universitario de León, León, España. 'Servicio de Anestesiología y Reanimación, Complejo Asistencial Universitario de León, León, España

\section{ABSTRACT}

Nowadays differentiation between central and peripheral origin in Parkinson's disease pain is considered as a clinical challenge. We present a long evolution Parkinson's disease case of a 71 years old woman. Treatment undergone by the patient consists in deep brain stimulation (DBS), drugs dopamine agonist, monoamine oxidase inhibitor-B (MAO-B) and catechol0 -methyltransferase inhibitor (COMT). The patient was referred to the pain unit due to an outbreak of continuous pain in the upper outer region of the left knee and no response to pharmacological nocioceptive pain treatment.

The patient was diagnosed with neuropathic pain after reviewing her clinical history, the physical examination and application of the DN4 scale. The chosen treatment was the application of a $179 \mathrm{mg}$ capsaicin patch over the region where she was experiencing the pain and it resulted in an improvement from week one which still persisting twelve weeks later.

Treatment with capsaicin patch was selected with the aim of avoid possible drugs interactions with her treatment.

As a conclusion, the high topical concentration of capsaicin has been found to be effective and safe in

\section{RESUMEN}

La enfermedad de Parkinson es un trastorno neurodegenerativo que comporta la alteración de las vías dopaminérgicas de los ganglios basales. El dolor que puede acompañar a la enfermedad de Parkinson se debe a mecanismos de depleción de las neuronas dopaminérgicas de la sustancia negra. Su etiología puede ser de origen central o periférico. Por ello, la aparición de dolor supone un reto clínico para distinguir entre ambos tipos y aplicar distintos tratamientos específicos.

Se ha descrito que el receptor vaniloide TRPV-1 de los astrocitos previene la degeneración progresiva de neuronas dopaminérgicas de la enfermedad de Parkinson y se asocia con una mejoría funcional y del dolor. Por otro lado, sabemos que la capsaicina es un potente activador exógeno del receptor vaniloide.

Presentamos el caso de una mujer de 71 años con enfermedad de Parkinson de larga evolución, en tratamiento con estimulación cerebral profunda y fármacos agonistas de la dopamina.

La paciente acudió a nuestra Unidad por la presencia de dolor localizado en la región superoexterna de la rodilla izquierda, de carácter continuo y sin respuesta a fármacos utilizados para tratar el dolor nociceptivo. Una vez completada la anamnesis y valorada la exploración
Alonso Cardaño A, García Rivera D, García Rodríguez A. Efecto analésico del parche de capsaicina al $8 \%$ a través del receptor vaniloide TRPV-1, en un paciente con enfermedad de Parkinson y dolor neuropático localizado. Rev Soc Esp Dolor. 2020;27(3):216-220
Recibido: 28-11-2019

Aceptado: 13-01-2020

Correspondencia: Alicia Alonso Cardaño aalonsocar@saludcastillayleon.es 
a patient with complicated treatment (DBS plus usual treatment).

Keywords: Parkinson, TRPV-1 receptor, capsaicin.

\section{INTRODUCCIÓN}

La enfermedad de Parkinson es un trastorno neurodegenerativo caracterizado por la pérdida de neuronas dopaminérgicas en la substantia niger de la pars compacta, dando lugar a anomalías motoras como temblor, rigidez y bradiquinesia, y también dolor. Los mecanismos por los que se produce dolor en la enfermedad de Parkinson incluyen la disminución de la actividad de las vías inhibitorias del dolor y la alteración de las vías dopaminérgicas de los ganglios basales, incluyendo los haces lateral y medial, responsables de la dimensión discriminativa y de la dimensión afectiva, autonómica y cognitiva, respectivamente.

Se han establecido diferentes subtipos de dolor en la enfermedad de Parkinson:

- Central

- Musculoesquelético

- Neuropático periférico

- Distónico

- Acatisia

El dolor en el paciente con enfermedad de Parkinson supone un desafío, ya que obliga en primer lugar a distinguir si el dolor está relacionado o no con la enfermedad, realizando en ocasiones el diagnóstico por exclusión.

\section{CASO CLÍNICO}

Mujer de 71 años con enfermedad de Parkinson idiopática avanzada de más de 20 años de evolución. Es portadora de un implante de electrodos subtalámicos desde 2013 para control de síntomas motores y realizaba tratamiento con fármacos agonistas de la dopamina, inhibidores de la monoaminooxidasa tipo B] e inhibidores de la catecol-0-metiltransferasa. Como consecuencia de su trastorno neurodegenerativo, sufría física y pruebas complementarias, se excluyó la causa orgánica. Se aplicó la escala DN4 para el dolor neuropático, obteniéndose una puntuación de 5 puntos. Se etiquetó como dolor neuropático periférico localizado. Se aplicó un parche de capsaicina $179 \mathrm{mg}$ sobre la región dolorosa de la rodilla, y la paciente fue revisada en consulta a los 7, 30 y 90 días, obteniéndose un alivio del dolor desde la semana 1. En la última revisión a los 90 días, persiste la mejoría clínica.

La capsaicina tópica de alta concentración se comportó como un fármaco agonista altamente selectivo del receptor vaniloide TRPV-1, ya que las neuronas sensitivas de la piel expresan dicho receptor. Por otro lado, el parche de capsaicina $8 \%$ permitió tratar a la paciente evitando posibles interacciones farmacológicas con su medicación habitual. En conclusión, la capsaicina tópica de alta concentración se mostró eficaz y segura en el tratamiento del dolor neuropático localizado en una paciente con enfermedad de Parkinson y difícil manejo.

Palabras clave: Parkinson, receptor TRPV-1, capsaicina.

caídas con frecuencia. Además presentaba signos y sintomas de osteoartritis en manos.

Acudió a nuestra Unidad por presentar una zona dolorosa en la región superior y externa de la rodilla izquierda, de 6 meses de evolución, de carácter insidioso, continuo y ardiente. En ocasiones presentaba sensación de acorchamiento a ese nivel. La paciente no refería irradiación. Lo consideraba como muy molesto y, a veces, insoportable. Había comenzado a tomar antinflamatorios no esteroideos y analgésicos opioides, sin experimentar ningún alivio del dolor. Escala verbal numérica: 8.

La exploración física evidenciaba una marcada hipersensibilidad en la zona dolorosa, con alodinia leve, en ausencia de edema o signos de flogosis. Se excluyeron traumatismos y alteraciones dérmicas o del sistema osteomuscular. Las pruebas radiológicas no presentaron hallazgos significativos. Las pruebas neurofisiológicas fueron normales.

Se administró la escala DN4 para dolor neuropático en la que se obtuvo una puntuación de 5 puntos, confirmando el diagnóstico y considerando caso de estudio al ser la puntuación $\geq 3$ puntos de los 10 posibles (Tabla I).

Una vez desestimada la causa orgánica local del dolor, pensamos en un subtipo de dolor relacionado con el Parkinson. El dolor no se correspondía con un trastorno musculoesquelético ni tampoco con acatisia o distonía, trastornos que no estaban presentes en nuestra paciente. De forma adicional, la respuesta a analgésicos indicados en dolor nociceptivo no obtuvo ninguna modificación en el dolor de la paciente.

Las características del dolor referidas por la paciente sugieren un componente neuropático y, además, se presenta a nivel periférico y bien localizado, lo que, junto con los resultados obtenidos en la escala DN4 $\geq 3$ puntos, nos hicieron sospechar un dolor neuropático periférico. 
TABLA I

RESULTADOS DEL CUESTIONARIO DN4

\begin{tabular}{|c|c|c|c|c|}
\hline & & & Sí & No \\
\hline \multirow{7}{*}{ Entrevista al paciente } & \multirow{3}{*}{$\begin{array}{l}\text { Pregunta } 1 \\
\text { ¿Tiene su dolor alguna de estas } \\
\text { características? }\end{array}$} & Quemazón & $x$ & \\
\hline & & $\begin{array}{l}\text { Sensación de frío } \\
\text { doloroso }\end{array}$ & & $x$ \\
\hline & & Descargas eléctricas & & $x$ \\
\hline & \multirow{4}{*}{$\begin{array}{l}\text { Pregunta } 2 \\
\text { ¿Tiene en la zona donde le duele alguno de } \\
\text { estos síntomas? }\end{array}$} & Hormigueo & $x$ & \\
\hline & & Pinchazos & $x$ & \\
\hline & & Entumecimiento & $\mathrm{x}$ & \\
\hline & & Escozor & & $x$ \\
\hline \multirow{3}{*}{$\begin{array}{l}\text { Exploración física } \\
\text { del paciente }\end{array}$} & \multirow{2}{*}{$\begin{array}{l}\text { Pregunta } 3 \\
\text { ¿Se evidencia en la exploración alguno de } \\
\text { estos signos en la zona dolorosa? }\end{array}$} & Hipoestesia al tacto & & $x$ \\
\hline & & Hipoestesia al pinchazo & & $x$ \\
\hline & $\begin{array}{l}\text { Pregunta } 4 \\
¿ E \text { El dolor se provoca o intensifica por...? }\end{array}$ & Roce & $x$ & \\
\hline
\end{tabular}

Con el diagnóstico de dolor neuropático periférico localizado en la región superior y externa de la rodilla izquierda, elaboramos un plan terapéutico.

Valoramos en primer lugar el tratamiento farmacológico, especialmente las posibles interacciones medicamentosas derivadas de añadir fármacos considerados de primera línea en el dolor neuropático, que podrían sumarse a los potenciales efectos secundarios de la abundante medicación dopaminérgica de la paciente, como alucinaciones, somnolencia o empeorar la sintomatología parkinsoniana. El carácter localizado del dolor y la escasa repercusión sistémica de la aplicación del parche de capsaicina $179 \mathrm{mg}$ nos hicieron decantar por este último tratamiento.

Tras seleccionar la zona de hipersensibilidad sobre la piel y obtener una plantilla en papel, se aplicó capsaicina $8 \%$ mediante un parche adaptado a esa zona en la cara superior y externa de la rodilla izquierda durante $60 \mathrm{~min}$, siendo muy bien tolerado por nuestra paciente. Únicamente presentó una reacción eritematosa leve y transitoria en el lugar de aplicación. El parche fue retirado siguiendo las indicaciones proporcionadas por la empresa de fabricación. Se entregaron instrucciones acerca de las precauciones que, sobre la piel tratada, debía tener en cuenta en los días posteriores.

Se realizó una llamada telefónica a los 7 días de la aplicación del parche de capsaicina $8 \%$, y la paciente nos comunicó un alivio del dolor de 3 puntos en la escala verbal. Fue revisada en consulta a las 4 semanas del tratamiento, en la que se apreció, además de una reducción de $2 \mathrm{~cm}$ en el perímetro de la zona de hiperalgesia que pudimos comparar con la plantilla previa a la aplicación del tratamiento, una puntuación de 4 medida en la escala verbal del dolor y una mejora en la calidad del sueño. En la actualidad, transcurridas 12 semanas de la aplicación del parche de capsaicina, la mejoría del dolor se mantiene.

\section{DISCUSIÓN}

La enfermedad de Parkinson es un trastorno degenerativo que acontece por la pérdida progresiva de las neuronas dopaminérgicas nigroestriales, dando lugar a alteraciones motoras principalmente, aunque también incluye síntomas no motores, entre los que destaca el dolor, que puede llegar a estar presente hasta en el $85 \%$ de los pacientes [1]. El dolor es uno de los síntomas que más afecta a la calidad de vida y complica la sintomatología motora, siendo el caso que presentamos un claro ejemplo de ello.

El primer paso a dar en el paciente con enfermedad de Parkinson y dolor es distinguir si este está relacionado o no con su trastorno neurodegenerativo (2). En nuestra paciente no existen signos radiológicos ni exploratorios que pudiéramos relacionar con traumatismo, artrosis u otra causa externa del dolor localizado en la rodilla, por lo que iniciamos un diagnóstico diferencial sobre los diferentes tipos de dolor asociados a la enfermedad de Parkinson.

La clasificación más actual del dolor asociado con el Parkinson se basa en la etiología del mismo, reconociendo 5 subtipos de dolor: musculoesquelético (70\%), neuropático (20\%), distónico (40\%), dolor central $(4,5-27 \%)$ y acatisia [3]. Otras clasificaciones se basan en la respuesta al tratamiento dopaminérgico, tal como lo describió Ford en 2010.

Los mecanismos por los que se produce dolor en la enfermedad de Parkinson comprenden una alteración del procesamiento a nivel de los ganglios basales y pérdida de neuronas de las vías dopaminérgicas, además de una reducción de la actividad del sistema inhibitorio descendente [4]. Es de especial interés el hecho de que estudios recientes reconocen el papel neuroprotector que desempeñan algunas células no neuronales como son los astrocitos ante la enfermedad de Parkinson. Los astrocitos expresan el receptor vaniloide TRPV-1, y 
se ha sugerido que la activación de dicho receptor pone en marcha la maquinaria neuroprotectora endógena in vivo. Este receptor es un canal catiónico no selectivo, altamente expresado en las neuronas sensoriales. El análisis de la substantia niger en enfermos de Parkinson sugiere que el sistema endógeno neuroprotector TRPV-1 y CNTF (factor neutrofilico ciliar) de los astrocitos y el CNTFR $\alpha$ (receptor alfa) de las neuronas dopaminérgicas respectivamente, debe tener relevancia en la enfermedad de Parkinson (5). El receptor vaniloide de los astrocitos interviene, por tanto, en la producción endógena del factor neutrofílico ciliar, que es responsable de la prevención de la degeneración de las neuronas dopaminérgicas y conduce a una mejora en el comportamiento del CNTFR $\alpha$ y en los síntomas asociados a la enfermedad.

La activación del receptor vaniloide TRPV-1, tanto a nivel endógeno como exógeno, previene la degeneración progresiva de neuronas dopaminérgicas de la enfermedad de Parkinson, y se asocia con una mejoría de la modulación funcional de las mismas y en la regulación de la neuroinflamación [6]. Este receptor está implicado en el dolor de los pacientes con Parkinson.

La capsaicina es un potente activador exógeno del receptor vaniloide, actuando como agonista del receptor TRPV-1, lo que lo convierte en una diana terapéutica primordial para tratar el dolor de los pacientes con enfermedad de Parkinson (7).

Nuestra paciente no presentaba rigidez ni movimientos incesantes involuntarios (acatisia), ni tampoco un origen osteomuscular del dolor. El dolor central es aquel no confinado al territorio de un nervio o raíz nerviosa, quemante y con parestesias, mal localizado, e implica una reducción en los niveles de respuesta a levodopa. En el caso que presentamos, la localización concreta del dolor nos llevó a considerarlo como un dolor neuropático periférico. Por otra parte, la utilización de la escala para la identificación de dolor neuropático actualmente recomendada con mayor grado de fiabilidad es el cuestionario DN4, con un 80-90\% de sensibilidad y especificidad. Nosotros utilizamos la versión española validada en 2007 por C. Pérez por la sencillez de uso, y nos permitió discriminar las características del dolor de nuestra paciente, obteniendo un resultado positivo, y por tanto, abordarlo con dianas terapéuticas de forma local [8].

El tratamiento con capsaicina está considerado como de segunda línea en el dolor neuropático [9], aunque nosotros barajamos este fármaco como opción destacada, puesto que nos permite la aplicación localizada en el foco doloroso con ausencia de síntomas neurológicos adicionales, permitiendo la administración concomitante de otros fármacos sin ocasionar interacciones medicamentosas y con un inicio de acción rápido y sostenido en el tiempo [10]. Los parches adhesivos dérmicos de capsaicina 179 mg liberan capsaicina sintética en elevada concentración directamente en la zona dolorosa, siendo este fármaco un agonista altamente selectivo del receptor vaniloide TRPV-1. Las neuronas sensitivas de la piel expresan dicho receptor, además de neuronas en ganglios de la raíz dorsal, a nivel medular y cortical 111. Por lo tanto, la activación de TRPV-1 por la capsaicina actuaría mediante neuroprotección al disminuir el estrés oxidativo derivado de la glía reactiva y el res- cate de neuronas dopaminérgicas del sistema nervioso afectado, produciendo una reducción de la sensación dolorosa. En el caso que presentamos, el dolor se redujo en un $50 \%$ con respecto al inicial, medido a través de la escala verbal, que disminuyó en 4 puntos.

La paciente objeto de nuestro estudio recibía terapia de estimulación cerebral profunda (DBS Deep Brain Stimulation) a través de electrodos implantados a nivel subtalámico. Está bien establecido que los resultados terapéuticos de la DBS son similares al tratamiento dopaminérgico, al ejercer un efecto modulador sobre el circuito de los ganglios basales [12]. La base fisiológica del efecto de la DBS sobre síntomas no motores en la enfermedad de Parkinson como la alteración del sueño, el dolor y la disautonomía, es compleja. La prevalencia del dolor con DBS parece disminuir entre un $70 \%$ y un $21 \%$, aunque la mayoría de los estudios concluye que los tipos de dolor que más alivio experimentan con la DBS son el distónico y el musculoesquelético, mientras que los subtipos central y neuropático apenas se modifican. Una de las limitaciones que supuso el sistema DBS en nuestro caso es la contraindicación para la realización de resonancias magnéticas y otros procedimientos intervencionistas a nivel de la extremidad dolorosa.

\section{CONCLUSIONES}

La aplicación del parche de capsaicina $8 \%$ puede permitir un alivio del dolor en los pacientes con enfermedad de Parkinson y dolor neuropático periférico, al comportarse como un activador exógeno del receptor TPRV-1 y contribuir a la inhibición de las células gliales reactivas productoras de estrés oxidativo y neuroinflamación.

La analgesia que puede producir el parche de capsaicina es de inicio rápido y mantenido en el tiempo, de fácil administración y sin provocar interacciones farmacológicas adicionales en el paciente polimedicado con fármacos dopaminérgicos.

La aplicación del parche de capsaicina 179 mg puede constituir un complemento a la estimulación cerebral profunda en el tratamiento del dolor neuropático periférico de los pacientes con enfermedad de Parkinson.

\section{CONFLICTO DE INTERESES}

Los autores declaran no tener ningún conflicto de intereses.

\section{BIBLIOGRAFÍA}

1. Vila-Cha N, Cavaco S, Mendes A, Goncalves A, Moreira I, Fernandes $\mathrm{J}$, et al. Unveiling the relationship between central parkinsonian pain and motor symptoms in Parkinson's disease. Eur J Pain. 2019;23(8):1475-85. DOI: 10.1002/ ejp. 1413

2. Raccagni C, Nonnekes J, Bloem BR, Peball M, Boehme C, Seppi K, et al. Gait and postural disorders in parkinsonism: a clinical approach. J Neurol [Internet]. 2019; [citado Nov 2019]. DOl: 10.1007/s00415-019-09382-1 doi: 10.1007/s00415-019-09382-1. 
3. Marques A, Attal N, Bouhassira D, Moisset X, Cantagrel $\mathrm{N}$, Rascol O, et al. How to diagnose parkinsonian central pain? Parkinsonism Relat Disord. 2019;64:50-3. DOI: 10.1016/j.parkreldis.2019.04.025.

4. Marrone MC, Morabito A, Giustizieri M, Chiurchiu V, Leuti A, Mattioli MC. TRPV1 channels are critical brain inflammation detectors and neuropathic pain biomarkers in mice. Nat Commun. 2017;8:a15292. DOI: 10.1038/ ncomms15292.

5. Nam JH, Park ES, Won SY, Lee YA, Kim KI, Jeong JY, et al. TRPV1 on astrocytes rescues nigral dopamine neurons in Parkinson's disease via CNTF. Brain. 2015;138(Pt 12):3610-22. DOI: 10.1093/brain/awv297.

6. Yoshida A, Furube E, Mannari T, Takayama Y, Kittaka H, Tominaga $M$, et al. TRPV1 is crucial for proinflammatory STAT3 signaling and thermoregulation-associated pathways in the brain during inflammation. Sci Rep. 2016;6(1):26088. DOI: 10.1038/srep26088.

7. Chung YC, Baek JY, Kim SR, Ko HW, Bok E, Shin WH, et al. Capsaicin prevents degeneration of dopamine neurons by inhibiting glial activation and oxidative stress in the MPTP model of Parkinson's disease. Exp Mol Med. 2017;49(3):e298. DOI: 10.1038/emm.2016.159.
8. Perez C, Galvez R, Huelbes S, Insausti J, Bouhassira D, Diaz $S$, et al. Validity and reliability of the Spanish version of the DN4 (Douleur Neuropathique 4 questions) questionnaire for differential diagnosis of pain syndromes associated to a neuropathic or somatic component. Health Qual Life Outcomes. 2007;5:66. DOl: 10.1186/1477-7525-5-66.

9. Bouchenaki H, Bègou M, Magy L, Hajj R, Demiot C. Pharmacological management of neuropathic pain. Thèrapie. 2019;74(6):633-43. DOI: 10.1016/j.therap.2019.04.003.

10. Blair HA. Capsaicin $8 \%$ dermal patch: a review in peripheral neuropathic pain. Drugs. 2018;78(14):1489-500. DOI: 10.1007/s40265-018-0982-7.

11. Gustorff B, Poole C, Kloimstein H, Hacker N, Likar R. Treatment of neuropathic pain with the capsaicin 8\% patch: Quantitative sensory testing (QST) in a prospective observational study identifies potential predictors of response to capsaicin 8\% patch treatment. Scand J Pain. 2013;4(3):138145. DOI: 10.1016/j.sjpain.2013.04.001.

12. Kurtis MM, Rajah T, Delgado LF, Dafsari HS. The effect of deep brain stimulation on the non-motor symptoms of Parkinson's disease: a critical review of the current evidence. NPJ Parkinsons Dis. 2017;3:16024. DOI: 10.1038/ npjparkd.2016.24. 